\title{
Network Effects in Online Marketplaces: The Case of Kiva
}

\author{
Haim Mendelson and Yuanyuan Shen
}

\begin{abstract}
Advanced information technologies have enabled the development of online marketplaces that connect businesses and people on a global scale. Much of the analysis of the adoption, growth and engagement on these marketplaces in the extant literature is based on the premise that they are characterized by network effects-a premise that has major implications for their deployment, implementation and management. In this paper we test this premise using data from Kiva, the world's largest online, peer-to-peer social lending marketplace. We find that while network effects are strong and significant during the early growth phase of the marketplace, they become weak or disappear once the marketplace stabilizes.
\end{abstract}

Keywords-Online marketplaces, network effects, peer-to-peer lending, online services.

\section{INTRODUCTION}

A DVANCED information technologies are changing the structure of economic activity, with many traditional processes being transformed through the use of electronic marketplaces. Activities such as buying, selling and lending are moving from the established but labor-intensive and inefficient brick-and-mortar format to online marketplaces that increase efficiency, transparency and effectiveness and are already a major sector of the economy. The research questions addressed in this paper are: $(i)$ are online marketplaces characterized by network effects? (ii) How does the answer depend on the growth phase of the marketplace? We address these questions using data from Kiva, the world's largest social lending marketplace.

Network effects, also referred to as network externalities, reflect a positive relationship between the installed base of users on a platform and its value to users [1],[2],[3]. They are direct when there is a direct positive relationship between the size of the installed base and the value to users within that installed base. The classic example is the telephone network: adding a new user to the network increases the number of potential calls users can make, which increases the utility users derive from the network [4]. Indirect network effects arise when $(i)$ the network is based on two complementary components, say $A$ and $B$; (ii) there is a positive relationship between the installed base of $B$ and the value to users of $A$, and (iii) there is a corresponding positive relationship between the installed base of $A$ and the value to users of $B$ [1]. This results in a positive feedback loop between the installed bases of $A$ and $B$ : an increase in the installed base of $A$ makes the

H. Mendelson (haim@stanford.edu) is with the Graduate School of Business, Stanford University, Stanford, CA 94305, USA (see https://www.gsb.stanford.edu/faculty-research/faculty/haim-mendelson)

Yuanyuan Shen (anashen@alumni.stanford.edu) is with the Graduate School of Business, Stanford University, Stanford, CA 94305, USA. network more attractive to the $B \mathrm{~s}$, and as more $B \mathrm{~s}$ join the network, it becomes more attractive to the $A$ s. This means that more $A$ s attract yet more $A$ s indirectly through the $B \mathrm{~s}$ - hence the term indirect. In this paper we test the existence of this positive feedback loop.

Network effects have a major impact on the way technology-based solutions are deployed and managed as they affect choices of efficiency, effectiveness and speed: in the presence of network effects, a highly-efficient and effective solution that does not achieve critical mass may fail regardless of its technical or economic merit. Further, if network effects are sustainable, a solution that manages to control a large user base may prevail even when it is inferior on a stand-alone basis [1]. Thus, network effects have a paramount impact on the deployment and management of platforms, and in particularon online marketplaces.

In a peer-to-peer online lending marketplace, prospective borrowers post loan requests online either directly, on their own, or indirectly, through marketplace partners. Lenders browse the loan requests and decide which loans they would bid on. Lenders who wish to fund a loan submit conditional or unconditional funding commitments to the marketplace. The marketplace then matches loan requests to funding commitments, funds some of the loans, and services them until they are repaid (or until they default). It is commonly assumed that such lending marketplaces are characterized by indirect network effects between lenders and borrowers, as more lenders increase the probability of a loan request being funded, and more borrowers make the market more attractive to lenders, who can better diversify their loans and are more likely to find a match they are willing to fund. The latter consideration is important on Kiva, where lenders seek to support entrepreneurs with particular characteristics, and with more entrepreneurs and loan requests on the site, a lender is more likely to find one she is willing to support.

Network effects were found in a variety of industries ranging from telecommunications to Information Technology (cf. [5], [6], [7]). However, while the theoretical literature views network effects as an inherent feature of online marketplaces, we could not identify an empirical study that directly confirmed their existence in online peer-to-peer lending marketplaces. In this paper, we narrow this gap by investigating whether network effects actually exist on Kiva and how they depend on the growth phase of the marketplace.

The rest of the paper is organized as follows. Section II is a Kiva overview. Section III outlines our research hypotheses. Section IV describes our data and test methodology. Section $\mathrm{V}$ presents our results. We briefly conclude in Section VI 


\section{KIVA}

Founded in October 2005, Kiva operates a website where entrepreneurs from developing countries post loans through field partners-microfinance institutions, social businesses, schools, and other non-profit organizations. Loans come from individual lenders from across the globe, primarily from developed countries. Between October 2005 and June 2019, Kiva funded $\$ 1.32$ billion in loans extended to 3.3 million borrowers from 1.8 million lenders. These loans had an impressive repayment rate approaching $97 \%$.

Each month, Kiva's field partners post on the Kiva website loan requests on behalf of the entrepreneurs they represent. Loan terms average 1.5 years. Lenders browse the loan requests and may contribute $\$ 25$ or more to fund the loans they select.

Loan requests remain posted on Kiva for up to 30 days. If a loan is not fully funded within that period, it expires and all lenders' commitments are refunded. If the loan is fully funded, Kiva's field partner sends the money to the entrepreneur. As of June 2016, about $95 \%$ of loan requests were fully funded. As the borrower repays the loan, the field partner returns the principal through Kiva to the lenders who funded it.

Kiva lenders are social investors who receive no interest and make no profit on their loans (however, Kiva's field partners may charge interest on the loans they make). Loans serve the needs of poor, under-served, or financially excluded (e.g., unbanked or underbanked) populations and aim to achieve a social or environmental impact.

We obtained our data from Kiva's data snapshot on build. kiva.org, augmented by querying Kiva's API. In addition to basic data on borrowers and prospective lenders, we have loanspecific information through June 2016. Our sample period is January 2007 to June 2016. In our sample, the majority $(84.8 \%)$ of loan requests come from Asia, Africa and South America while most $(89.4 \%)$ lenders come from developed countries in North America and Europe. As a macroeconomic control, our regressions use the effective yield on the ICE BofAML Emerging Markets Corporate Plus Index [8], which is available on a daily basis and is expected to influence loan funding in emerging markets (we also used the GDP growth rate and unemployment rate, which turned out insignificant).

\section{RESEARCH HYPOTHESES}

In this paper, we formulate two key hypotheses on potential network effects and then test them using data from Kiva. As discussed above, the theory of network effects implies a positive feedback loop between the number of lenders and the amount of open loans (measured by their number or aggregate dollar amount): with more lenders, the platform should attract more loan requests, and with more loan requests, the platform should attract more lenders. This results in two key hypotheses:

Hypothesis 1: The dollar amount and number of open loans on Kiva should increase in the lagged number of active lenders.

Hypothesis 2: The number of active lenders on Kiva should increase in the lagged number and amount of open loan requests.

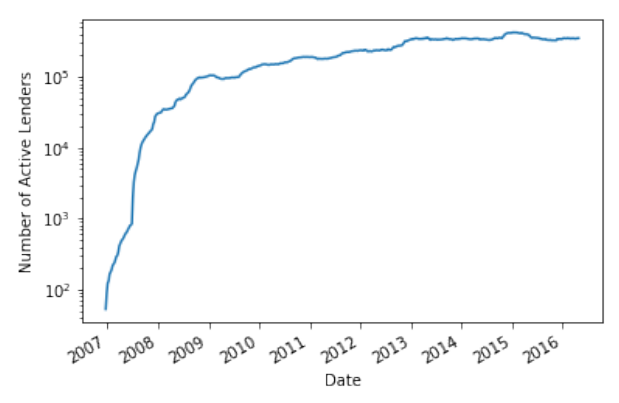

Fig. 1. Number of active lenders on Kiva

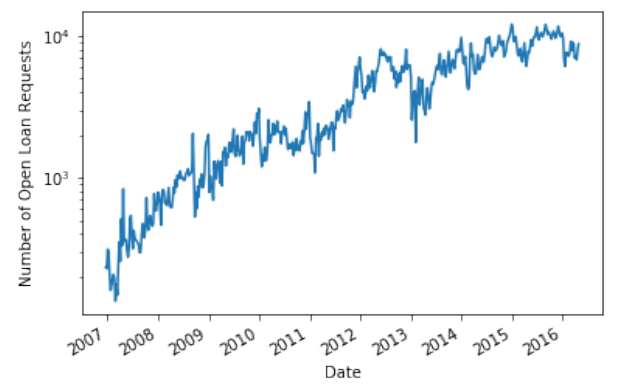

Fig. 2. Number of loan requests open on Kiva

Network effects and the associated feedback loop require both Hypotheses to hold.

\section{Data And Methodology}

We construct weekly time series for Kiva's performance over our sample period (2007 - 2016). We identify two phases in the development of the Kiva platform: a growth phase covering the first half of our sample period, and a more stable phase during the second half of our sample period. During the growth phase, both the amount of loans requested and the amount funded grow quickly. Then, the growth in both supply and demand flatten out. Further, during the second subperiod, the gap between the number of loans requested and the number of loans funded becomes larger.

Figure 1 shows the number of active lenders (i.e., those who have bid on at least one loan in the past six months) and Figure 2 shows the number of open loan requests on Kiva each week over our sample period, both on a logarithmic scale. The figures show how growth has abated between the earlier growth period and the latter stable period, when the number of active lenders flattens out and the growth in open loan requests deteriorates.

These patterns show distinct differences between the earlier growth period and the latter stability period. While the empirical network effects literature typically finds them at the early growth phases of new technologies, it does not recognize the stark differences between the early growth and stability periods. Madden and Dalzell [9] study the early growth of mobile telephony and attribute differences between high- and low-income countries to non-linear network effects.

We argue that network effects should be more prominent during the earlier growth period, when the growing installed 
base is a key driver of adoption. Once the platform stabilizes, we expect other factors and tactical moves undertaken by the platform (e.g., field partner selection, budgeted loan amounts, etc.) to overtake the network effects as drivers of performance. Indeed, while peer-to-peer lending has been growing rapidly around the globe [10], Kiva has experienced a declining loan fulfillment rate, and during the 2011-12 period it started honing its business model, actively managing demand and supply down to the level of the types of loans made [11], [12]. In addition, Kiva was facing increased competition from new social microfunding sites (e.g., MyC4 in Europe, Wokai in China and MicroPlace in the U.S.), as well as from forprofit lending sites that catered to entrepreneurs (e.g, Zopa in Europe and CreditEase in China; these sites, which charge interest, competed with Kiva since many field partners charge interest to the entrepreneurs they serve). In addition, Feldman et al. show theoretically that the performance of peer-to-peer systems can degrade significantly as a result of user turnover [13]. We thus expect our network effects hypotheses 1 to 2 to hold during the early growth period and to become substantially weaker or altogether disappear during the latter stability period.

To test for these different behaviors, we divide our observations into two halves, (i)January 2007 to August 2011 and (ii) September 2011 to June 2016. Table I displays the correlation matrix among our key variables for the two sample subperiods.

TABLE I

CORRELATIONS BETWEEN THE NUMBER OF ACTIVE LENDERS, THE DOLLAR AMOUNT AND THE NUMBER OF LOAN REQUESTS

\begin{tabular}{lcc}
\hline Variable & Amount of Loan Requests & No. Loan Requests \\
\hline Jan 2007 - Aug 2011 & & \\
No. Active Lenders & 0.87 & 0.87 \\
Amount of Loan Requests & - & 0.99 \\
\hline Sept 2011 - June 2016 & & \\
No. Active Lenders & 0.46 & 0.46 \\
Amount of Loan Requests & - & 0.95 \\
\hline
\end{tabular}

In Table I, we observe a strong correlation between the number of active lenders and the number and dollar amount of loan requests during the first subperiod. These correlations substantially decline in the second subperiod. Due to the correlations among our key explanatory variables, we test each of our hypotheses separately. For Week $t$, we denote by $n_{t}$ the number of active lenders (defined as those who placed at least one bid over the past six months), by $a_{t}$ the dollar amount of open loan requests, and by $l_{t}$ the number of open loan requests. We estimate (heteroskedasticity-corrected) OLS regressions using the specification below to test Hypothesis 1 that the dollar amount of loan requests increases in the number of active lenders:

$$
\log \left(a_{t}+1\right)=\alpha_{0}+\alpha_{1} \log \left(n_{t-1}+1\right)+\overrightarrow{\alpha_{3}} \vec{x}_{t-1}+\epsilon_{t},
$$

where the vector $\vec{x}_{t-1}$ comprises the default rate on Kiva loans as of the end of Week $t-1$, the effective yield on the ICE BofAML Emerging Markets Corporate Plus Index [8], dummy variables representing the year of $t$, and a trend variable.

An alternative test of Hypothesis 1 focuses on the relationship between the number of loan requests and the number of active lenders:

$$
\log \left(l_{t}+1\right)=\beta_{0}+\beta_{1} \log \left(n_{t-1}+1\right)+\vec{\beta}_{3} \vec{x}_{t-1}+\zeta_{t} .
$$

To test Hypothesis 2 that the number of active lenders increases in the dollar amount of loan requests, we estimate the regression:

$$
\log \left(n_{t}+1\right)=\gamma_{0}+\gamma_{1} \log \left(a_{t-1}+1\right)+\vec{\gamma}_{2} \vec{x}_{t-1}+\omega_{t} .
$$

Likewise, we test whether the number of active lenders increases in the number of open loan requests by estimating the equation:

$$
\log \left(n_{t}+1\right)=\kappa_{0}+\kappa_{1} \log \left(l_{t-1}+1\right)+\vec{\kappa}_{3} \vec{x}_{t-1}+\psi_{t} .
$$

In Equations (1) through (4), $\epsilon_{t}, \zeta_{t}, \omega_{t}, \eta_{t}$ are random noise.

\section{Results}

Table II shows the results of our OLS estimations using White's method to account for heteroskedasticity [14].

As hypothesized, we observe positive and stronglysignificant coefficients for our network effect variables during Kiva's growth period: a $1 \%$ increase in the number of active lenders results in a $0.31 \%$ increase in the dollar amount and a $0.46 \%$ increase in the number of open loan requests. A $1 \%$ increase in the dollar amount of open loan requests leads to a $0.17 \%$ increase in the number of active lenders, and a $1 \%$ increase in the number of loan requests leads to a $0.32 \%$ increase in the number of active lenders. These results are both economically meaningful and strongly statistically significant, confirming our hypotheses. Given that both hypotheses hold, we have the feedback loop confirming the existence of network effects during the growth period.

For the second subperiod (September 2011 through June 2016), the network effect coefficients become small and, for the most part, insignificant (the exception is the coefficient of the number of open loan requests in Eq. (4), which is significant at the $90 \%$ level). Based on equations (1)-(3), both hypotheses are rejected. Because a rejection of either one of our hypotheses leads to the rejection of network effects, we conclude that there are no meaningful network effects during the second subperiod. These results are consistent with our argument for the differences between the two subperiods (Section IV).

Equations (3)-(4) use the number of active lenders to estimate the dependent variable, which leads to autocorrelated residuals. To address this issue, we reestimated equations (3)-(4) by differencing the number of active lenders, using $\left(n_{t}-n_{t-1}\right)$ as our dependent variable. The results are shown in columns (3a) and (4a) of Table II. The main difference between the two specifications is that in equation (3a), the significance of the amount of loan requests declines in the first subperiod and increases in the second. Our conclusion remains intact: there are strong and significant network effects in the first subperiod whereas in the second subperiod, there are no network effects, as Hypothesis 1 fails to hold. 
TABLE II

RESULTS FOR HYPOTHESES 1 AND 2

\begin{tabular}{|c|c|c|c|c|c|c|c|c|c|c|c|c|}
\hline \multirow[b]{2}{*}{ Regressors } & \multicolumn{6}{|c|}{ Jan 2007 - Aug 2011} & \multicolumn{6}{|c|}{ Sept 2011 - June 2016} \\
\hline & Eq. (1) & Eq. (2) & Eq. (3) & Eq. (3a) & Eq.(4) & Eq. (4a) & Eq. (1) & Eq. (2) & Eq. (3) & Eq. (3a) & Eq.(4) & Eq.(4a) \\
\hline Intercept & $\begin{array}{c}9.67 * * * \\
(0.89)\end{array}$ & $\begin{array}{l}1.52^{+} \\
(0.79)\end{array}$ & $\begin{array}{c}8.03 * * * \\
(0.71)\end{array}$ & $\begin{array}{c}-10,432^{+} \\
(6,118)\end{array}$ & $\begin{array}{c}8.21 * * * \\
(3.87)\end{array}$ & $\begin{array}{l}-7,040 \\
(3,046)\end{array}$ & $\begin{array}{c}11.93^{* * *} \\
(3.79)\end{array}$ & $\begin{array}{c}4.22 \\
(0.15)\end{array}$ & $\begin{array}{l}12.48 * * * \\
(17,294)\end{array}$ & $\begin{array}{c}-35,236^{*} \\
(0.09)\end{array}$ & $\begin{array}{l}12.55^{* * * *} \\
(10,908)\end{array}$ & $-18,462^{+}$ \\
\hline No. Active Lenders & $0.31 * * *$ & $\begin{array}{c}0.46^{* * * *} \\
(0.08)\end{array}$ & - & - & - & - & 0.13 & 0.22 & - & - & - & - \\
\hline Amount Loan Requests & - & - & $0.17 * *$ & $866.83^{+}$ & - & - & - & - & 0.02 & $2,485^{*}$ & - & - \\
\hline No. Loan Requests & - & - & $\begin{array}{c}(0.0) \\
- \\
-\end{array}$ & $\begin{array}{c}(4 / 0.40) \\
- \\
-\end{array}$ & $\begin{array}{c}0.32^{* * * *} \\
(0.06)\end{array}$ & $\begin{array}{c}1,248^{* * *} \\
(482)\end{array}$ & - & - & $\begin{array}{c}(0.01) \\
- \\
-\end{array}$ & $\begin{array}{c}(1,1 / 1) \\
- \\
-\end{array}$ & $\begin{array}{c}-\overline{-}+2^{+} \\
(0.01)\end{array}$ & $\begin{array}{c}- \\
2,446^{+} \\
(1,299)\end{array}$ \\
\hline Default Rate & $\begin{array}{l}-1.67 \\
(0.79)\end{array}$ & $\begin{array}{l}-2.23 \\
(6.03)\end{array}$ & $\begin{array}{l}-3.34 \\
(2.30)\end{array}$ & $\begin{array}{c}5,578 \\
(41,893)\end{array}$ & $\begin{array}{l}-3.88 \\
(2.49)\end{array}$ & $\begin{array}{c}4,542 \\
(42,179)\end{array}$ & $\begin{array}{c}102.65 * * * \\
(18.71)\end{array}$ & $\begin{array}{c}96.22 * * * \\
(16.57)\end{array}$ & $\begin{array}{l}6.50^{*} \\
(3.11)\end{array}$ & $\begin{array}{c}-26,047 \\
(263,670)\end{array}$ & $\begin{array}{l}6.08^{+} \\
(3.11)\end{array}$ & $\begin{array}{c}-12,015 \\
(268,525)\end{array}$ \\
\hline Interest Rate & $\begin{array}{c}-0.02^{+} \\
(0.01)\end{array}$ & $\begin{array}{l}-0.004 \\
(0.01)\end{array}$ & $\begin{array}{c}0.01 \\
(0.01)\end{array}$ & $\begin{array}{l}103.17 \\
(71.12)\end{array}$ & $\begin{array}{c}0.01 \\
(0.01)\end{array}$ & $\begin{array}{c}92.16 \\
(70.55)\end{array}$ & $\begin{array}{l}-0.02 \\
(0.06)\end{array}$ & $\begin{array}{l}-0.03 \\
(0.06)\end{array}$ & $\begin{array}{c}-0.06 * * * \\
(0.01)\end{array}$ & $\begin{array}{l}-260.01 \\
(818.33)\end{array}$ & $\begin{array}{c}-0.06^{* * *} * \\
(0.01)\end{array}$ & $\begin{array}{c}-222.5 \\
(817)\end{array}$ \\
\hline Trend & $\begin{array}{c}0.01 \\
(0.001)\end{array}$ & $\begin{array}{c}0.01 \\
(0.001)\end{array}$ & $\begin{array}{c}0.01 * * * * \\
(0.001)\end{array}$ & $\begin{array}{c}-7.46 \\
(10.28)\end{array}$ & $\begin{array}{c}0.005^{* * * * *} \\
(0.001)\end{array}$ & $\begin{array}{l}-13.73 \\
(10.93)\end{array}$ & $\begin{array}{c}0.001 \\
(0.002)\end{array}$ & $\begin{array}{c}0.002 \\
(0.002)\end{array}$ & $\begin{array}{l}-0.001^{*} \\
(0.0003)\end{array}$ & $\begin{array}{c}-79.34 * * * * \\
(24.46)\end{array}$ & $\begin{array}{c}-0.0005^{*} \\
(0.0003)\end{array}$ & $\begin{array}{c}-82.83 * * * \\
(25.15)\end{array}$ \\
\hline Year Dummy & Yes & Yes & Yes & Yes & Yes & Yes & Yes & Yes & Yes & Yes & Yes & Yes \\
\hline$R^{2}$ & 0.91 & 0.91 & 0.94 & 0.04 & 0.94 & 0.05 & 0.55 & 0.56 & 0.80 & 0.07 & 0.80 & 0.07 \\
\hline
\end{tabular}

\section{Vi. Conclusion}

This paper studies network effects on Kiva by testing the existence of a positive feedback loop between the number of active lenders and the amount (in dollar value or number) of open loans. We identify strong and positive network effects during Kiva's initial stage of growth. The network effects essentially disappear in the latter period, when Kiva has reached greater stability. Our results suggest that network effects are particularly important during the initial growth phase of a marketplace platform. As growth abates and competition becomes fierce, the importance of network effects declines and other tactical, behavioral and competitive factors play an increasing role. This difference between the early growth and stability periods is largely ignored in the literature.

What are the implications for the way marketplaces such as Kiva are deployed and managed? Early on, network effects are all-important, customer acquisition and speed are key success factors, and the primary objective is to grow and achieve critical mass. However, the marketplace cannot rest on its laurels following its initial growth. Rather, the network effects weaken or even disappear, forcing the marketplace to engage in constant analysis, exploration and optimization. In the particular case of Kiva, social and behavioral factors such as the ones studied in [15] are key drivers of user behavior, and the marketplace has to dynamically optimize its features so as to keep attracting new users and increase the engagement of existing users.

Our analysis is preliminary as it has a number of limitations. First, one may use other variables to study the prevalence of network effects. Second, our results are based on a single research site, and it is worth examining to what extent they extend to other network settings and marketplaces. Further, more sophisticated econometric techniques may be used to study the drivers of marketplace adoption. These extensions provide fruitful avenues for future research.

\section{REFERENCES}

[1] H. Mendelson, "Platform business models: Text and case studies," Electronic Business Case Collection, Kindle Edition,
https://www.amazon.com/Platform-Business-Models-ElectronicCollection-ebook/dp/B078H3CDW9, 2017.

[2] M. L. Katz and C. Shapiro, "Systems competition and network effects," Journal of economic perspectives, vol. 8, no. 2, pp. 93-115, 1994. doi: 10.1257/jep.8.2.93

[3] A. Hagiu and J. Wright, "Multi-sided platforms," International Journal of Industrial Organization, vol. 43, pp. 162 - 174, 2015. doi: https://doi.org/10.1016/j.ijindorg.2015.03.003. http://www.sciencedirect. com/science/article/pii/S0167718715000363

[4] J. Rohlfs, "A theory of interdependent demand for a communications service," The Bell Journal of Economics and Management Science, pp. 16-37, 1974. doi: 10.2307/3003090

[5] E. Brynjolfsson and C. F. Kemerer, "Network externalities in microcomputer software: An econometric analysis of the spreadsheet market," Management Science, vol. 42, no. 12, pp. 1627-1647, 1996. doi: $10.1287 / \mathrm{mnsc} .42 .12 .1627$

[6] T. H. Hannan and J. M. McDowell, "The determinants of technology adoption: The case of the banking firm," The RAND Journal of Economics, pp. 328-335, 1984. doi: 10.2307/2555441

[7] C.-P. Lin and A. Bhattacherjee, "Elucidating individual intention to use interactive information technologies: The role of network externalities," International Journal of Electronic Commerce, vol. 13, no. 1, pp. 85108, 2008. doi: 10.2753/JEC1086-4415130103

[8] ICE Benchmark Administration Limited (IBA), "Ice bofaml emerging markets corporate plus index effective yield [bamlemcbpiey]," 2019, retrieved from FRED, Federal Reserve Bank of St. Louis, https://fred. stlouisfed.org/series/BAMLEMCBPIEY.

[9] G. Madden, C.-N. Grant, and B. Dalzell, "A dynamic model of mobile telephony subscription incorporating a network effect," Telecommunications Policy, pp. 133-144, 2004. doi: 10.1016/j.telpol.2003.12.002

[10] B. Lloyd and M. Surana, "Online marketplaces for loans are growing rapidly. should banks be worried?" https://www.hardingloevner.com/fundamental-thinking/ online-marketplaces-for-loans-are-growing-rapidly-should-banks-be-worried/, accessed: 2019-05-07.

[11] Kiva Blog, "Expiring loans," 2012, retrieved in May 2019 online from https://pages.kiva.org/blog/ qa-expiring-loans-credit-limits-and-the-evolution-of-kiva.

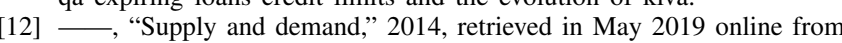
http://blog.kiva.org/supply-and-demand\#findingtrouble.

[13] M. Feldman, C. Papadimitriou, J. Chuang, and I. Stoica, "Free-riding and whitewashing in peer-to-peer systems," IEEE Journal on selected areas in communications, vol. 24, no. 5, pp. 1010-1019, 2006. doi: 10.1109/JSAC.2006.872882

[14] H. White, "A heteroskedasticity-consistent covariance matrix estimator and a direct test for heteroskedasticity," Econometrica, vol. 48, no. 4 pp. 817-838, 1980

[15] H. Mendelson, K. Moon, and Y. Shen, "Behavioral and social effects in a crowdfunding marketplace," Working Paper, Graduate School of Business, Stanford University, 2019. 